\title{
Disposition Kinetics of Cefquinome in Calves after a Single Intramuscular Bolus Dose
}

\author{
Hemvati, Pratishtha Sharma* and Ashok Gaur
}
Department of Veterinary Pharmacology and Toxicology, College of Veterinary and Animal Science, Rajasthan University of Veterinary and Animal Sciences (RAJUVAS), Bikaner-334001, Rajasthan, India

*Corresponding author

\begin{abstract}
A B S T R A C T
Keywords

Calves,

Cefquinome, Pharmacokinetics

\section{Article Info}

Accepted: 07 December 2018 Available Online: 10 January 2019

Cefquinome is fourth generation cephalosporin developed exclusively for veterinary use. The present research was aimed to investigate the disposition kinetic profile of cefquinome at the dose level of $2 \mathrm{mg} \cdot \mathrm{kg}^{-1}$ body weight following single intramuscular administration. Cefquinome concentrations in plasma were determined by microbiological assay technique using Kocuria rhizophila MTCC 1541 as the test organism. The plasma concentrationtime profile following intramuscular administration was best described by onecompartment open model. The peak plasma concentration $\left(\mathrm{C}_{\max }\right)$ of $5.79 \pm 0.35 \mu \mathrm{g} \cdot \mathrm{ml}^{-1}$ was achieved at $1.10 \pm 0.17 \mathrm{~h}\left(\mathrm{t}_{\max }\right)$. The absorption half-life $\left(\mathrm{t}_{1 / 2 \mathrm{ka}}\right)$, elimination half-life $\left(\mathrm{t}_{1 / 2 \beta}\right)$, area under plasma drug concentration-time curve (AUC) and apparent volume of distribution $\left(\mathrm{Vd}_{\text {area }}\right)$ of cefquinome were $0.25 \pm 0.04 \mathrm{~h}, 1.68 \pm 0.16 \mathrm{~h}, 16.02 \pm 1.11$ $\mu \mathrm{g} . \mathrm{ml}^{-1} . \mathrm{h}$ and $0.30 \pm 0.03 \mathrm{~L} . \mathrm{kg}^{-1}$, respectively. Cefquinome @ $2 \mathrm{mg} . \mathrm{kg}^{-1}$ at 12 hour dosing interval is sufficient to maintain desired therapeutic level in calves considering $\mathrm{MIC} \leq 0.25$ $\mu \mathrm{g} \cdot \mathrm{ml}^{-1}$.
\end{abstract}

\section{Introduction}

Cefquinome is a potent and efficacious fourth generation aminothiazolyl cephalosporin with broad spectrum of activity against Grampositive and Gram-negative bacteria, developed exclusively for veterinary use including food animals (Murphy et al., 1994). It has certain advantages over the earlier cephalosporins which include extended spectrum activity, penetration ability into the periplasmic space of Gram negative bacteria, enhanced binding with penicillin- binding proteins and improved bioavailability. It has time-dependent bactericidal effect, as shown by $\beta$-lactam antibiotics, and is stable against chromosomal as well as plasmid-encoded $\beta$ lactamases that are produced by a majority of clinically important bacteria (Limbert et al., 1991; Bryskier, 1997; Thomas et al., 2006).

The chemical modifications in the basic cephalosporin structure made cefquinome a zwitterion, the property that facilitates rapid penetration across the biological membranes, including the porins of the bacterial cell wall, 
improving bioavailability and the enhancing spectrum of antimicrobial activity, in comparison with second and third generation cephalosporins (Sader and Jones, 1993; Shpigel et al., 1997; Guerin-Faublee et al., 2003; Thomas et al., 2006). The principal chemical difference between cefquinome and third generation cephalosporins (e.g. cefotaxime or ceftriaxone) is the introduction of a quarternary ammonium side chain attached at C-3 of the beta-lactam nucleus (Bryskier, 1997).

Cefquinome is time-dependent bactericidal agent and its pharmacokinetic behavior is dose-independent (Limbert et al., 1991; Yuan et al., 2011). It shows rapid and complete absorption following intramuscular administration, widely distributed throughout body tissues and fluids including bronchial mucosal tissues, peritoneal fluid, biliary fluid and milk (Ehinger et al., 2006; Uney et al., 2011). Cefquinome has excellent penetration in udder with experimentally-induced mastitis in cows with Escherichia coli (Shpigel et al., (1997). Cefquinome is excreted mainly by kidneys within $24 \mathrm{~h}$ of administration, 60 and $80 \%$ of the administered dose was recovered in the urine of mice and dogs, respectively (Limbert et al., 1991).

Pharmacokinetic studies of cefquinome have been conducted in other species but there is paucity of pharmacokinetic data in calves, so the present study was undertaken to generate disposition kinetic parameters of cefquinome after intramuscular administration in calves and to determine the appropriate dosage regimen in calves.

\section{Materials and Methods}

\section{Drug}

Cefquinome $2.5 \%$ ready-to-use suspension for intramuscular injection of a multinational commercial brand was purchased from local market. It gives $25 \mathrm{mg}$ cefquinome per $\mathrm{ml}$.

\section{Animals}

Five clinically healthy male calves of 4-6 months age and weighing 40-60 kg were used. Animals were kept under good hygienic condition and maintained on green fodder, concentrated mixture and water was provided ad libitum. None of the animals were been treated with antimicrobials for one month prior to the trial. The study was approved by the Institutional Ethics committee of Rajasthan University of Veterinary and Animal Sciences, Bikaner.

\section{Experimental design}

Each animal was given a single intramuscular bolus dose of $2 \mathrm{mg} \cdot \mathrm{kg}^{-1}$ body weight on the lateral aspect of neck. Blood samples were collected in EDTA containing test tubes from jugular vein at $0,0.08,0.17,0.33,0.5,0.75$, $1.0,1.5,2,4,6,8,10,12$ and $24 \mathrm{~h}$ after administration of the drug. Blood samples were centrifuged at $3000 \mathrm{rpm}$ for $15 \mathrm{~min}$ to separate the plasma. Plasma samples were stored at $-20^{\circ} \mathrm{C}$ until analysis.

\section{Drug assay}

Cefquinome concentrations in plasma samples were determined by microbiological assay method described by Arret et al., (1971) using Kocuria rhizophila MTCC 1541 as test organism which is equivalent of Micrococcus luteus ATCC 9341 (El-Badawy et al., 2015). Six wells were made at equal distance in standard petri-dishes containing $25 \mathrm{ml}$ of seeded agar. The wells were filled with $100 \mu \mathrm{l}$ of either the test samples or cefquinome standard concentrations. The plates were incubated at $37^{\circ} \mathrm{C}$ for $24 \mathrm{~h}$. The inhibition zone diameters were measured and the cefquinome concentrations in the test samples 
were extrapolated from the standard curve. The lowest detection limit of the cefquinome assay was $0.1 \mu \mathrm{g} / \mathrm{ml}$. Standard curve were prepared using antibacterial-free pooled plasma collected from the animals prior to the experiment. Cefquinome standard solutions of concentrations of $0.098,0.195,0.391,0.78$, $1.56,3.125,6.25,12.5$ and $25 \mu \mathrm{g} . \mathrm{ml}^{-1}$ were prepared. Semi-logarithmic plots of the zone of inhibitions versus standard cefquinome concentrations were linear with typical correlation coefficient of 0.990 .

\section{Pharmacokinetic analysis}

Based on the apparent visual curve fitting of semi-logarithmic plots of plasma cefquinome concentrations versus time data of individual animals following administration by intramuscular route, pharmacokinetic determinants were determined. Plasma cefquinome levels-time data after attainment of peak levels were best fitted to a one compartment open model using the mono exponential equation:

$\mathrm{Cp}=\mathrm{Be}^{-\beta \mathrm{t}}-\mathrm{A}^{\prime} \mathrm{e}^{-\mathrm{Kat}}$,

Where $\mathrm{Cp}$ is the plasma concentration at time ' $\mathrm{t}$ '; $\mathrm{Ka}$, and $\beta$ are absorption, and elimination rate constants; $\mathrm{A}^{\prime}$ and $\mathrm{B}$ are the zero time intercepts of absorption and elimination phases, respectively; and " $\mathrm{e}$ " is base of the natural logarithm.

The rate constants, so derived, were used to calculate the respective half life values. Other pharmacokinetic parameters were computed according to the standard formulae (Baggot, 2001; Gibaldi and Perrier, 2007). Values of all the pharmacokinetic parameters have been expressed as the mean $\pm \mathrm{SE}$.

\section{Results and Discussion}

Plasma cefquinome concentration versus time data is plotted on a semi logarithmic graph shown in Figure 1. Following intramuscular administration of cefquinome, the drug concentration of $0.95 \pm 0.18 \mu \mathrm{g} . \mathrm{ml}^{-1}$ was observed with in $2.5 \mathrm{~min}$ which gradually increased and reached at peak plasma concentration $\left(\mathrm{C}_{\max }\right)$ of $5.37 \pm 0.40 \mu \mathrm{g} \cdot \mathrm{ml}^{-1}$ at $1 \mathrm{~h}\left(\mathrm{t}_{\max }\right)$. After reaching to maximal, plasma levels declined gradually to $0.28 \pm 0.03 \mu \mathrm{g} . \mathrm{ml}^{-}$ ${ }^{1}$ at $8 \mathrm{~h}$. cefquinome concentrations around the MIC value of $0.25 \mu \mathrm{g} \cdot \mathrm{ml}^{-1}$ were observed up to $8 \mathrm{~h}$ only.

The plasma concentration versus time profile following single intramuscular dose of cefquinome was best described by a mono compartment open model which is similar to that described in goats (Champawat et al., 2018), camel (Al-Taher, 2010) and dog (Zhou et al., 2015). However, a two-compartment open model was described in sheep (Tohamy, 2011), piglets ( $\mathrm{Li}$ et al., 2008) and ducks (Yuan et al., 2011).

Different disposition kinetic parameters have been summarized in Table 1. Following IM administration, absorption of cefquinome was apparently very fast as revealed by initial plasma drug concentrations with in $2.5 \mathrm{~min}$ of drug administration (Figure 1) and also the respective absorption half life $\left(\mathrm{t}_{1 / 2 \mathrm{Ka}}\right)$ values of $0.25 \pm 0.04 \mathrm{~h}$ and the $\mathrm{t}_{\max }$ value of $1.10 \pm 0.17$ (Table 1). Comparable value of $t_{1 / 2 \mathrm{Ka}}$ have been reported in goats $(0.29 \pm 0.04 \mathrm{~h})$ (Champawat et al., 2018) and rabbit $(0.28 \pm 0.02 \mathrm{~h})$ (Shalaby et al., 2014). However, higher $\mathrm{t}_{1 / 2 \mathrm{Ka}}$ values of cefquinome have been observed in sheep (Rana et al., 2015) and camel (Al-Taher, 2010) with corresponding values of $0.61 \pm$ $0.10 \mathrm{~h}$ and $4.35 \pm 0.27 \mathrm{~h}$, respectively. Lower $\mathrm{t}_{1 / 2 \mathrm{Ka}}$ value of $0.14 \pm 0.05 \mathrm{~h}$ was reported in beagle dogs (Zhou et al., 2015).

Elimination half-life $\left(t_{1 / 2 \beta}\right)$ of cefquinome in calves in the present study was found to be $1.68 \pm 0.16 \mathrm{~h}$ following IM administration. It is comparable to $t_{1 / 2 \beta}$ in ducks $(1.79 \pm 0.13 \mathrm{~h})$ (Yuan et al., 2011). 
Table.1 Pharmacokinetic determinants of cefquinome in calves following a single intramuscular bolus dose at the rate of $2 \mathrm{mg} \cdot \mathrm{kg}^{-1}$ body weight

\begin{tabular}{|l|l|l|}
\hline Parameter & Unit & Mean \pm S.E. \\
\hline $\mathbf{A}^{\prime}$ & $\mu \mathrm{g} \cdot \mathrm{ml}^{-1}$ & $10.43 \pm 1.35$ \\
\hline Ka & $\mathrm{h}^{-1}$ & $2.97 \pm 0.41$ \\
\hline $\mathbf{t}_{1 / 2 k a}$ & $\mathrm{~h}$ & $0.25 \pm 0.04$ \\
\hline $\mathbf{B}$ & $\mu \mathrm{g} \cdot \mathrm{ml}^{-1}$ & $8.46 \pm 1.03$ \\
\hline $\boldsymbol{\beta}$ & $\mathrm{h}^{-1}$ & $0.42 \pm 0.03$ \\
\hline $\mathbf{t}_{1 / 2 \boldsymbol{\beta}}$ & $\mathrm{h}$ & $1.68 \pm 0.16$ \\
\hline $\mathbf{C}_{\mathbf{m a x}(\mathbf{o b s})}$ & $\mu \mathrm{g} \cdot \mathrm{ml}^{-1}$ & $5.79 \pm 0.35$ \\
\hline $\mathbf{t}_{\mathbf{m a x}(\mathbf{o b s})}$ & $\mathrm{h}$ & $1.10 \pm 0.17$ \\
\hline AUC & $\mu \mathrm{g} \cdot \mathrm{ml}^{-1} \cdot \mathrm{h}$ & $16.02 \pm 1.11$ \\
\hline AUMC & $\mu \mathrm{g} \cdot \mathrm{ml}^{-1} \cdot \mathrm{h}^{2}$ & $46.26 \pm 4.88$ \\
\hline MRT & $\mathrm{h}$ & $2.88 \pm 0.23$ \\
\hline Vd & $\mathrm{L} \cdot \mathrm{kg}^{-1}$ & $0.30 \pm 0.03$ \\
\hline Cl & $\mathrm{ml} . \mathrm{kg}^{-1} \cdot \mathrm{h}^{-1}$ & $122.35 \pm 7.10$ \\
\hline
\end{tabular}

Fig.1 Semi logarithmic plot of mean $(n=5)$ plasma concentration versus time curve of cefquinome given intramuscularly in calves at the dose of $2 \mathrm{mg} \cdot \mathrm{kg}^{-1}$ body weight.

Data presented are mean \pm SE of five animals

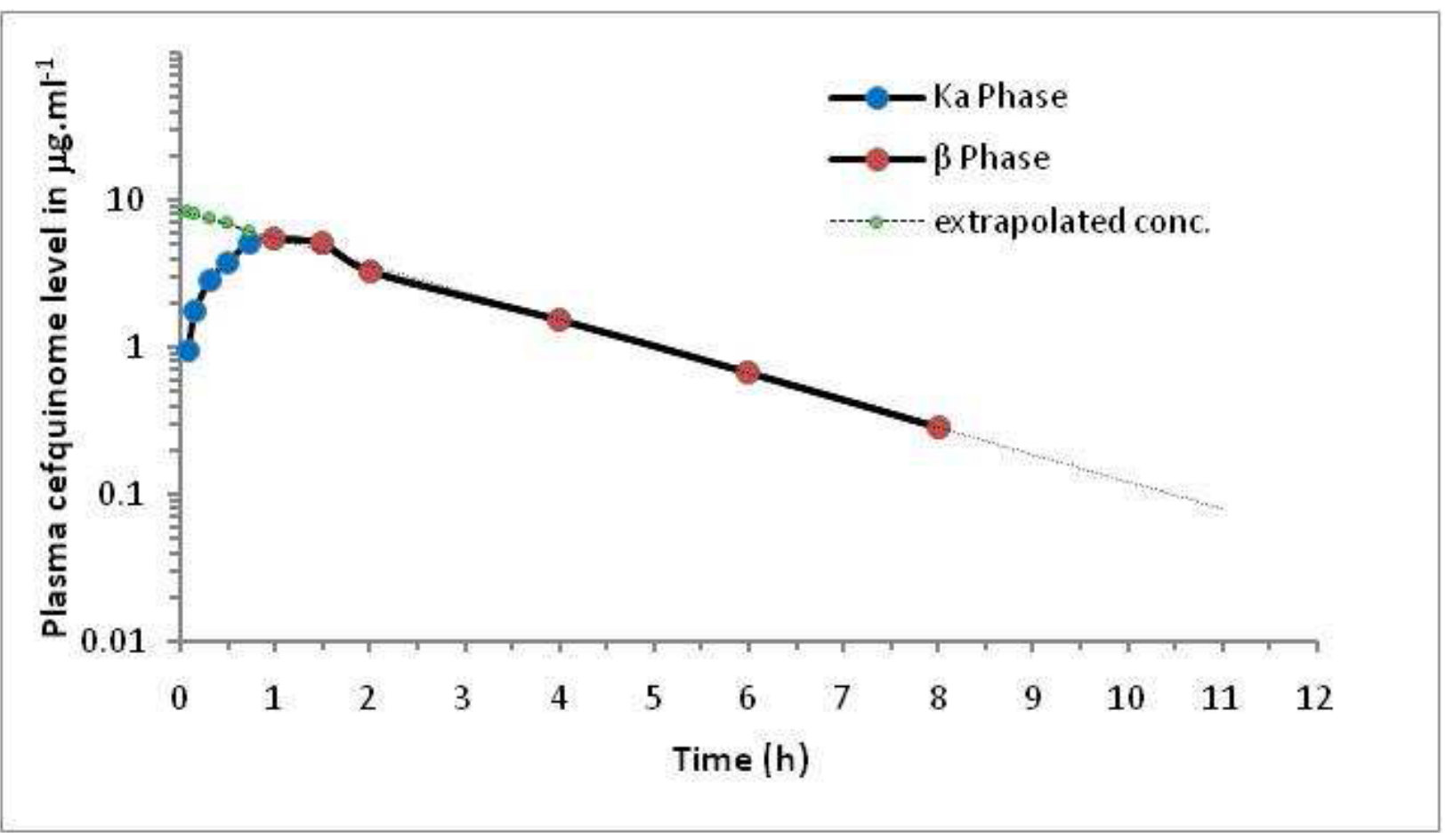


Higher $t_{1 / 2 \beta}$ values have been reported in buffalo calves $(3.73 \pm 0.10 \mathrm{~h})$ (Venkatachalam et al., 2018), sheep (12.29 \pm $2.62 \mathrm{~h}$ ) (Rana et al., 2015), piglet (4.36 \pm 2.35 h) (Li et al., 2008) and camel (10.24 $\pm 0.8 \mathrm{~h})$ (Al-Taher, 2010). Lower value of $t_{1 / 2 \beta}(1.48 \pm$ $0.04 \mathrm{~h})$ has been reported in goats (Champawat et al., 2018).

The AUC values of cefquinome in calves after IM administration were calculated to be $16.02 \pm 1.11 \mu \mathrm{g} . \mathrm{ml}^{-1}$.h. Almost similar values of AUC of cefquinome have been reported in sheep (Rana et al., 2015), goats (Champawat et al., 2018) and camel (Al-Taher, 2010) but higher values of AUC were reported in chickens (El- Sayed et al., 2015) and rabbits (Shalaby et al., 2014). Lower value of AUC was reported in Beagle dogs (Zhou et al., 2015).

In conclusion, cefquinome is a beta-lactam antimicrobial and acts as a time-dependent bactericidal drug (Thomas et al., 2006), the most appropriate $\mathrm{PK} / \mathrm{PD}$ parameter to describe drug efficacy is the time during which the drug's concentration exceeds the MIC (T>MIC) (McKellar et al., 2004; Zonca et al., 2011). It is generally recommended that T>MIC should be at least $50 \%$ of the dosage interval to ensure an optimal bactericidal effect (Winther et al., 2011). In the present study, the plasma levels above the minimum inhibitory concentration (MIC) level of $\geq 0.25$ $\mu \mathrm{g} \cdot \mathrm{ml}^{-1}$ were maintained up to $8 \mathrm{~h}$ following intramuscular administration of cefquinome. Cefquinome, therefore, at the dose rate of 2 mg. $\mathrm{kg}^{-1}$ body weight intramuscularly and at twelve hour dosing interval is recommended to ensure an optimal bactericidal effect in calves.

\section{Acknowledgement}

The authors thankfully acknowledge the facilities, financial help and animal provided by the Principal Investigator of CEVPAM, Dean CVAS Bikaner and officer in-charge, LRS Kodamdesar, RAJUVAS, Bikaner.

\section{References}

Arret, B., Johnson, D. P. and Krishbaum, A. (1971). Outline of details for microbiological assays of antibiotics: Second revision. J. Pharm. Sci. 60(11), 1689-1694.

Al-Taher, A. Y. (2010). Pharmacokinetics of cefquinome in camels. J. Anim.Vet. Adv. 9(4), 848-852.

Baggot, J. D. (2011). Principles of drug disposition in domestic animals: The Physiological Basis of Veterinary Clinical Pharmacology, W.B. Saunders Company, Philadelphia (USA).

Bryskier, A. (1997). New concepts in the field of cephalosporins: C-3'quaternary ammonium cephems (Group IV). Clin. Microbiol. Infect., 1997, 3 (Suppl 1), S1-S6.

Champawat, M., Sankhala, L. N., Sharma, P., Gaur, A. (2018). Pharmacokinetic of single dose intramuscular administration of cefquinome using microbiological assay in goats, $\mathbf{J}$. Entomol. Zool Stud. 6(3), 1825-1828.

Ehinger, A. M., Schmidt, H. and Kietzmann, M. (2006). Tissue distribution of cefquinome after intramammary and systemic administration in the isolated perfused bovine udder. Vet. J. 172(1), 147-53.

El-Badawy, S. A., Amer, A. M., Kamel, G. M., Eldeib, K. M. and Constable, P. D. (2015) Comparative pharmacokinetics using a microbiological assay and high performance liquid chromatography following intravenous administration of cefquinome in lactating goats with and without experimentally induced Staphylococcus aureus mastitis. Small Rumin. Res., 133, 67-76. 
El-Sayed, M. G. E., El-Komy, A. A. E, Mobarej, E. A. and Ahmed, El-Mahdy, A. M. (2015). Pharmacokinetics and tissue residues of cefquinome in normal and Salmonella entretidis infected chickens. World J. Pharm. Pharm. Sci. 4 (10), 1974-1987.

Gibaldi, M. and Perrier, D. (2007). Pharmacokinetics, 2nd edn., Marcel Deccar Inc., New York (USA).

Guerin-Faublee, V., Carret, G. and Houffschmitt, P. (2003). In vitro activity of 10 antimicrobial agents against bacteria isolated from cows with clinical mastitis. Vet. Rec. 152(15), 466-471.

Li, X. B., Wu, W. X., Su, D., Wang, Z. J., Jiang, H. Y. and Shen, J. Z. (2008). Pharmacokinetics and bioavailability of cefquinome in healthy piglets. J. Vet. Pharmacol. Ther. 31(6), 523-527.

Shalaby, M. A., Goudah, A., Gihan, M. K. and Hassan, A. S. (2014). Disposition kinetics of cefquinome in healthy rabbits following intramuscular and oral administration. World J. Pharm. Sci. 4(1), 263-274.

Limbert, M., Isert, D., Klesel, N., Markus, A., Seeger, K., Seibert, G. and Schrinner, E. (1991). Antibacterial activities in vitro and in vivo and pharmacokinetics of cefquinome (HR 111V), a new broadspectrum cephalosporin. Antimicrob. Agents Chemother. 35(1), 14-19.

McKellar, Q. A., Sanchez Bruni, S. F. and Jones, D. G. (2004). Pharmacokinetic/ pharmacodynamic relationships of antimicrobial drugs used in veterinary medicine. J. Vet. Pharmacol. Therap. 27, 503-514.

Murphy, S.P., Erwin, M.E. and Jones, R.N. (1994). Cefquinome (HR 111V) In vitro evaluation of a broad-spectrum cephalosporin indicated for infections in animals. Diagn. Microbiol. Infect. Dis.20, 49-55.
Rana, M. P., Sadariya, K. A. and Thaker, A. M. (2015). Effect of tolfenamic acid coadministration on pharmacokinetics of cefquinome following intramuscular administration in sheep. Vet. arhiv. 85(3), 283-292.

Sader, H. S. and Jones, R. N. (1993). The fourth-generation cephalosporins: antimicrobial activity and spectrum definitions using cefpirome as an example. Antimicrobic. Newsletter. 9(2): 9-16.

Shpigel, N. Y., Levin, D., Winkler, M., Saran, A., Ziv, G. and Bottner, A. (1997). Efficacy of cefquinome for treatment of cows with mastitis experimentally induced using Escherichia coli. J. Dairy Sci. 80, 318-323.

Thomas, E., Thomas, V. and Wilhem, C. (2006). Antibacterial activity of cefquinome against equine bacterial pathogens. Vet. Microbiol. 115, 140147.

Tohamy, M. A. (2011). Age-related intramuscular pharmacokinetics of cefquinome in sheep. Small Rumin. Res. 99, 72-76.

Uney, K., Altan, F. and Elmas, M. (2011). Development and validation of a high performance liquid chromatography method for determination of cefquinome concentrations in sheep plasma and its application to pharmacokinetic studies. Antimicrob. Agents Chemother. 55(2), 854-859.

Venkatachalam, D., Dumka, V. K. and Ranjan, B. (2018). Pharmacokinetics of a single intramuscular injection of cefquinome in buffalo calves. J. Vet. Pharmacol. Therap. 41, 155-158.

Winther, L., Baptise, K. E. and Friis, C. (2011). Antimicrobial disposition in pulmonary epithelial lining fluid of horses, part 3rd Cefquinome. J. Vet. Pharmacol. Therap. 34, 482-486.

Yuan, L., Sun, J., Wang, R., Sun, L., Zhu, L., 
Luo, X., Fang, B. and Liu, Y. (2011). Pharmacokinetics and bioavailability of cefquinome in healthy ducks. Am. J. Vet. Res. 72(1), 122-126.

Zhou, Y. F., Zhao, D. H., Yu, Y., Yang, X., Shi, W., Peng, Y. B., and Liu, Y. H. (2015). Pharmacokinetics, bioavailability and PK/PD relationship of cefquinome for Escherichia coli in
Beagle dogs. J. Vet. Pharmacol. Therap. 38, 543-548.

Zonca, A., Gallo, M., Locatelli, C., Carli, S., Moroni, P., Villa, R. and Cagnardri, P. (2011). Cefquinome sulphate behaviour after intramammary administration in healthy and infected cows. J. Dairy Sci. 94, 3455-3461.

\section{How to cite this article:}

Hemvati, Pratishtha Sharma and Ashok Gaur. 2019. Disposition Kinetics of Cefquinome in Calves after a Single Intramuscular Bolus Dose. Int.J.Curr.Microbiol.App.Sci. 8(01): 494-500. doi: https://doi.org/10.20546/ijcmas.2019.801.053 